\title{
Speed in the sustainable city
}

\author{
P. Yildiz \\ Department of Interior Architecture and Environmental Design, \\ Hacettepe University, Turkey
}

\begin{abstract}
Speed is the basis of life style in the sustainable city development. The concept of speed in the image of the city is so important among optimal and multidisciplinary living styles. Recently life styles are strongly affected by the concept of speed and therefore the designing process in the scale of city planning has started to be based on that factor. This is also the case in the newly developing cities.

Speed will be analyzed by the ecological statement of the city, transportation, visual perception and recognition, aesthetical needs, multifunctional usages of common spaces and the formation and orientation of city centers in the sustainable cities.

Speed is the basic principle in artificial intelligence. In this study, the speed factor with some examples on sustainable developed cities and criticizing this factor by making proposals will be discussed. Ankara, the capital city of Turkey, will also be analyzed. Showing examples of speed in city life style will bring together contemporary solutions as a result of this study.

The most important thing is to mention the speed factor together with regular, comfortable and peaceful relaxing spaces. The ideal combination of speed and comfort is the basic aim of the study.

The term speed does not only refer to transportation or time factor but also to the multidisciplinary and flexible usage of surroundings as well as aesthetic value and visual recognition.
\end{abstract}

Keywords: sustainable city, speed, transportation, optimal, common spaces, multidisciplinary, visual perception.

\section{Introduction}

Cities are places characterized by a physical dimension, an identity and an image. Cities bear a geographic, demographic, physical and economic dimension 
that nourish and determine its internal functioning and its role. A city is the definition of the systematic organization of a large scale space of communities who are organized to live together and share the same common places among the related image and circumstance. A city, in order to be contemporary, has to carry some basic properties which lead the societies to live well and peacefully. A sustainable city should:

-have functioning infrastructures,

-have responsive to the needs of the people,

-contain alternatives from a wider perspective,

-have the capacity to identify problems and produce concrete solutions,

-require active citizenship and good governance,

-recycle; generate systems and natural resources,

-have common spaces with multifunctional usages and multicultural identity etc.

The sustainable meanings of cities are the properties regarding the flexible and optimal usages of external spaces in that city, the multicultural perspective of the city, the historical aspect with the futuristic solutions, the aesthetical value of city environments, and the time criteria to reach the dynamism of a city life. One of the most important factors to reach sustainable meaning in a city is speed.

In today's world, life styles are hardly affected by the necessity of time and the lack of it. The dynamism of city life is based around speed formation, which is the basis and the necessity of contemporary life style. Urban sustainability is not a simple environmental quality objective, but forms a triangular relationship between economic, social and ecological principles [3].

\section{The multidimensional formation of speed in the sustainable city}

Speed should be adapted to the city from various perspectives which come together to maintain sustainability factor. In a sustainable city the formation of speed from various ways and the process of its circulation indicate the high quantities of a city. These different approaches to analyze speed in city life can be summarized as follows:

\subsection{Solutions regarding the ecological basis of the city}

The ecological statement is very important regarding transportation. The geographical phrase should be taken into consideration to maintain the optimal usage. If the city is by sea level, then the transportation vehicles should be designed accordingly. For example, cycling ways could be added taking the place of pedestrian ways to be faster. Transportation with the basis of ecological structure brings together solutions related with sea transportation, tunnel formation, bridge usage, transportation through air way like tele-ferric, cycling ways where the topography is by sea level and also sea shore usage etc. 


\subsubsection{The local transportation in the city}

At the turn of the last century more sophisticated transport technologies were introduced, electrified trains and commuter trains, and these were followed by underground electric railways. This generated a new wave of suburban development, reinforced by the need to solve the emerging social housing problem. The result of this development was the emergence of late publictransport cities (e.g.: London, Paris, Berlin, New York etc.). Transportation brings people and goods to people, returning enormous benefits to economies [1]. However, transportation also comes with significant undesirable side effects, particularly in terms of air pollution in urban areas and emissions of greenhouse gasses, which can impact on global climate change.

One of the ways to analyze the speed factor in city environment is solving the problem by transportation. Transportation in city life can be supplied in many ways to reach sustainability. The fastest and at the same time the most comfortable solutions can be reached. Transport has significant effects on the environment that should be addressed explicitly in the design of programs and systems in general. The transportation factor can be explained under two headings:

-Pedestrian: The pedestrian ways in the city environment should have some properties as follows:

The relationship of the pedestrian ways with the motorways must be strong but bring together the solutions of safety, noise and ergonomics.

The pedestrian ways must be:

-well designed with appropriate dimensions;

-with a path of green axes between the highways which could separate the ways from each other;

-should be non-limited to be faster like the help of the bridges where needed, etc).

-By common vehicles: The transportation by motorways and high ways could be adequate and safe and without blocking each other in order to avoid traffic-jam, especially in rush hours. If motorways are blocking each other, then the intersection should be solved by downgrade or upgrade circulation systems. The vehicles for transportation process should be adequate with the ecology, geographical statement of the city, climate, etc.

\subsubsection{Sustainable transport with the term speed brings together the} following solutions Transport and communications in the urban area are not necessarily a burden or threat, but rather they are vital for sustained economic development. It ought to be emphasized that cities in both the developed and the developing world will not favor urban sustainability by discouraging urban mobility through artificial, inflexible and generalized regulations. Mobility is a necessary consequence of the need for accessibility, which in turn offers the necessary conditions for vital cities as islands of opportunities. Thus, the often assumed conflict between urban transport and the environment has to be looked at also from the viewpoint of dynamic positive externalities. 


\subsubsection{Designing the city environments regarding climate}

The climate criterion is another factor to be recognized reaching solutions by the help of speed. A city's environmental properties decline the city's life style regarding:

-Transportation. In the cold regions suburbanization is integrated with city life like placing the entrances of shopping malls in the subways. An example of this can be seen in Canada.

-Activities related with climate that bring dynamism to the city.

-The energy transformation system regarding climate is another factor that brings faster solutions regarding speed. For example, the renewable energy systems are optimal quantities of the usage of natural resources, which let us gain time. The effort and time for fulfilling the loss of a source is minimized as this process is supplied in a natural circulation that decreases manpower energy.

\subsection{The visual perception and recognition in the city}

Perception is another factor parallel with the term speed. If a city has strong perceptional elements spread around, then the process of activities could be faster. The solutions for the recognition matter in the city must be well designed to understand the city activities (cultural, artistic, social etc.). If the recognition of the activities held in the city becomes easier, then the speed of the activity in the city can increase. To strengthen the perceptional recognition [5]:

-there should be enough numbers of billboards,

-the billboards should be placed ideally in order to be seen from all sides. For example, when a billboard announcing an activity is placed in the motorway and with a degree turning its face to the road, then it can be seen by many more people which leads us to a faster and better recognition process.

\subsection{The aesthetical value of the city}

This factor can be analyzed under two main titles:

-The restoration and prevention of the historical features of the city could accelerate the rate of usage and functionality in a city where spaces are valuable. The historical aspect of a city should be renewed and loaded with functions commonly needed in city life. This practice brings together speed factor as the functional needs are supplied by aesthetical and valuable spaces. So both the aesthetical and functional needs of city life are solved together.

-The usage of contemporary means of art in transportation vehicles: While the dynamism of city life circulates in a fast rhythm the aesthetical needs could sometimes neglected and the loss of this criterion arises thereby. The artistic practice inserted on transportation vehicles supply the aesthetical value of environments.

\subsection{The flexible and multidisciplinary usage of common spaces in the city life style}

In the sustainable city there should be some common spaces for common activities relating to cultural, social, artistic etc. issues. Open space provides a 
break from the continual battering that occurs to a human being from the crush of the urban environment. Furthermore large tracts of open land existing contiguously to developed areas preserve the quality of the overall environment.

The common spaces should be designed multidisciplinary to be flexible for different usages in order to gain time for different activities at the same place, and that is another formation of speed in the city environments. The same common place should be optimally formed through contemporary means. This leads to maintaining the optimal usage of places. The term speed arises here when a city is more active, dynamic and becomes a transition between different people. The three kinds of common space increase the capacity of relationship where speed is formed:

-Complementary spaces; linking cities performing different roles within the spatial division of labour (relatively specialized in different functions)

-synergy spaces; linking cities performing similar roles and allowing the integration of the local markets (e.g. the international financial centres, acting on a unique virtual worldwide market, art cities, linked within tourist itineraries), -Innovation spaces; linking cities cooperating on common projects (e.g. airports, railways, etc.) [3].

-Suburbanization is another functional necessity for faster process.

\subsection{The formation and orientation of city centers}

In big cities a basic city center is usually the most active and recognized space for everyone and most of the needs could be supported in this area. In sustainable city basis the centers for cities should be in different focal points of the city map. This could bring together the activities to be spread around the city life and the supporting of the needs from different sources that leads to the gaining of time and speed factor. The city centers should be formed in opposite focal points and coordinates of the newly developing cities. These coordinates indicate the city's maximizing ability also.

One of the solutions for urban diseconomies of scale and the increasing contradiction between the abstract node function of the city and its heavy physical realm is to think about the integrated way in which the general city is formed:

-The single centers have to bear a diversification of functions, possibly linked with each other in order to contain inside the center the widest possible share of trips. In this respect monofunctional centers should be avoided in order to be faster in life styles and maximize trip generation with respect to other centers.

-the centers should be linked with each other through a network of effective transport links, organized both in a radia and an orbital way with respect to the major city-centre.

-each center should keep or develop its specific image and character, in order to work as a magnet [2].

\subsection{Using terraces so as to fill the loss of green (green roof planning)}

In sustainable cities the need for green areas and the adequate spreading of them are other factors to be recognized if the solutions regarding green areas came 
closer then the effort for reaching these types of natural spaces could be minimised then the multifunctional areas with green usage would bring speed to formal ordinary life styles.

\section{The sustainable cities as sample regarding speed criterion}

To analyze the speed on some sustainable developed cities the first criterion is to examine transportation. In the conflict between private motorization and collective transport systems several cities made an explicit choice pro private car, with a result of low density in individualized urban sprawl (Los Angeles, Dallas etc). This led to called auto oriented cities, in which public transport was bound to decline. Other cities however, adopted a different urban transport systems model and tried to cope with the new wave of urban industrialisation by developing more appropriate public transit systems (e.g.: Paris, London, Tokyo, New York etc.).

Later on when cities started to grow (e.g., Brussels, Frankfurt, Milano, Rotterdam, San Francisco), they adopted a hybrid policy by opting for both private and public transport. Although a significant part of urban transport in the centre is served by public transport, the share of private transport in suburban areas is as high as in Los Angeles. Such cities have a mixture of various models of public transport. In view of the high social costs of congested urban centers, a new phenomenon has in more recent years emerged the edge city, which means also a concentrated suburbanization of offices and shops towards suburban areas, which are either car-dependent (e.g.: Milano, Munich, Toronto etc.) or public transport dependent (e.g.: Tokyo, Amsterdam, Zurich). The sustainable cities could be accepted as a union of internalization, multinationalization and globalization. More recently, in presence of an acceleration in the process of international integration due to political, economic and institutional reasons, cities are taking up anew crucial role; the role of gateways in the internalization process of their surrounding regions [4].

The speed criterion on some sustainable developed cities can also be recognized by especially the preservation of open spaces. The most common properties that can be listed are:

-Restraints on central city growth,

-Request for private parking availability in newly rebuilt residential lots.

-The multifunctional land-use/transport planning, (e.g.: suburbanization in Canada)

-Compact city and urban containment,

-Multi-centric city formation, (e.g.: New York)

-Mixed land-uses,

-Designed growth areas and new towns etc.

The other recognition of speed criterion on some sustainable developed cities can be seen on multifunctional usage of common spaces. The Rockefeller Center in New York is a sample of it. In winter time the space provides ice-skating facility while, in summer time it is used for coming together and to organize some external fairs and exhibits at the same place. This optimal usage in the city can bring dynamism and activity to city life which leads the city to gain speed. 


\section{Ankara the capital city of Turkey}

In this study, we can analyze the sustainable developing features of the capital city of Turkey. The advantages and disadvantages of Ankara in the basis of sustainability could be summarized as follows. Firstly the advantages of the city are:

-The geographical statement of Ankara is adequate for speed criterion as it is in the middle of Turkey, and, as a capital city, it is nearly the same distance to reach all the cities when compared with each other. So the general location of this city meets the demands of speed.

-The formation of the city centers in Ankara has newly started to develop. Because of the high population rise in Turkey cities are developing so fast but without taking attention to green usage. Ankara is also developing very fast especially on some axes. The high population and the need for housing increase day by day and that's why the city is developing in an accelerated way. But one factor is dominant as the city center formation is another factor to be recognized. The centers have started to be located at different coordinates of the city and that started to bring speed factor as the need of the people have started to be met nearby the streets where they live.

-The subways are developing so as to help maintain the speed factor.

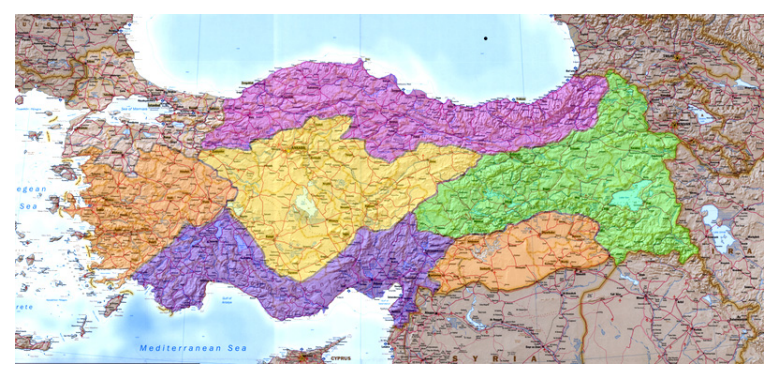

Figure 1: $\quad$ The general map of Turkey.

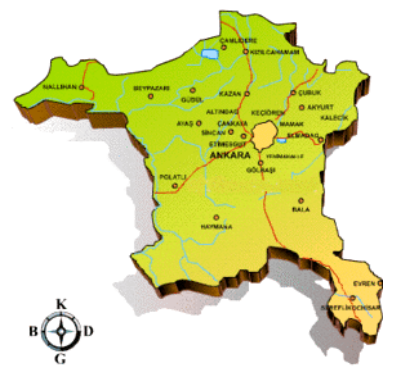

Figure 2: The Map of Ankara, The capital city of Turkey. 


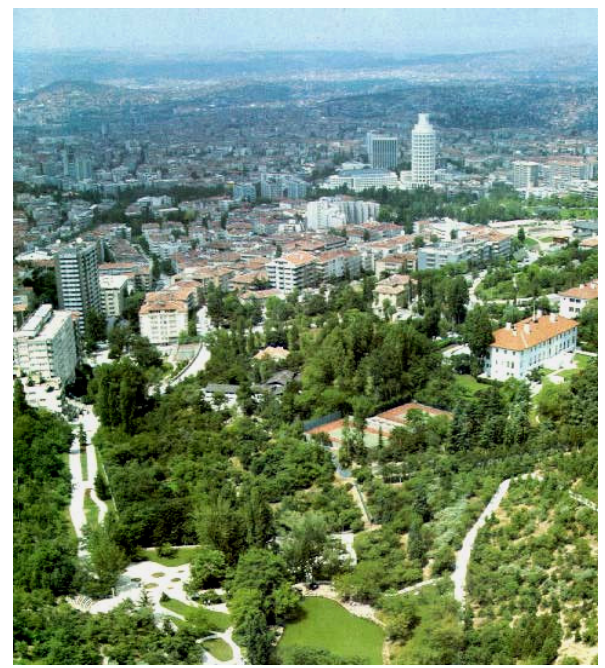

Figure 3: A view from a hill of Ankara.

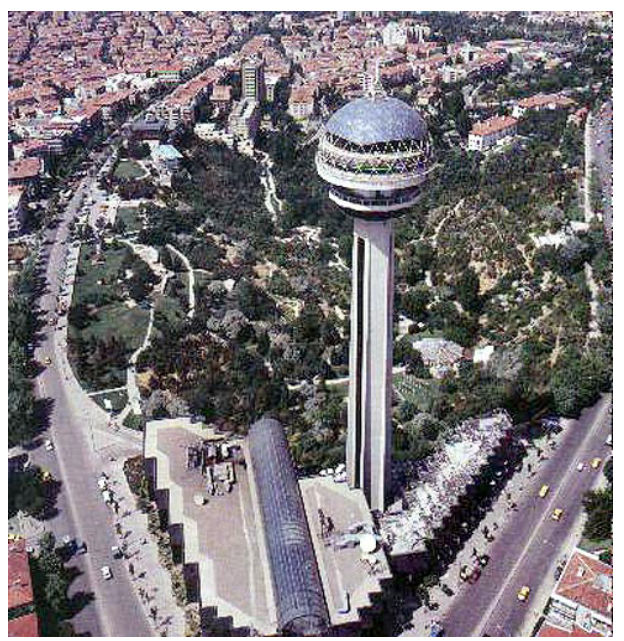

Figure 4: Another view from a hill of Ankara, the Atakule Tower.

-The billboards and visual recognition have newly started to be designed according to ideal ways of perception.

-The historical features of the city are functional at the present and that brings aesthetical and functional solutions together.

Some of the disadvantages are as follows:

-The transportation and traffic problem barriers for the speed of ordinary life styles. In 1990 the Turkey's railway decided to get rid of their steam locomotives 
and to replace them with more modern machinery. Fortunately, all the enormous beasts that used to pull the carriages where put together in a museum (Figure 5).

-There are still many places which lack subway and a railway transit system.

-The cultural and social activities should be better organized for people around the city, which make them attend the activities in a faster way.

-The city is not proper for touristic activities and that can slow down the cultural and artistic activities, economy and sustainability, etc.

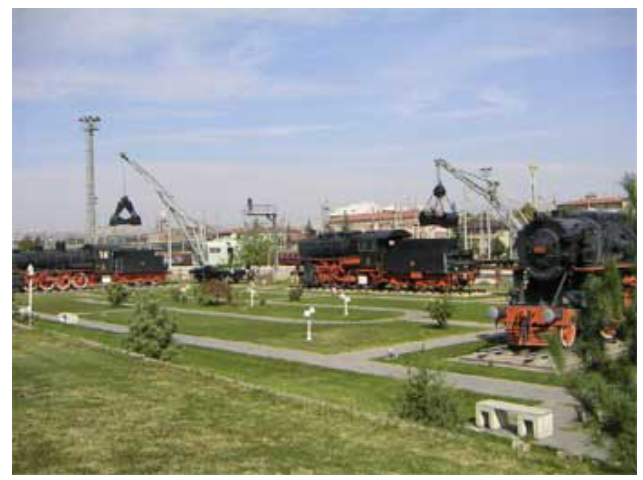

Figure 5: The traditional transportation system with locomotives, now being exhibited in a museum.

Based on these examples we can say that Ankara is developing fast but should take care and great attention to designing with natural factors and aesthetical values also. Sustainability is a concept for contemporary appliances and is hardly effective on city planning but on one hand it takes time to be reached because the results could take some time to be seen as the development of the city takes too much time because of the conditions of multicultural and economical factors. And on the other hand the importance of it is recently started to be understood and is newly being integrated in city planning and general regulations of environmental design process.

\section{Result}

The results of this study indicate that sustainability factor is highly based on speed. Speed should be in every usage and condition of the modern city. The factors that are the solution of speed are as follows:

-A fast, systematical and contemporary urban transportation system with safe and comfortable practice would be speedy.

-Designing on the basis of the ecology of the city brings faster solutions.

-As the formation of city centers increase, than the needs are welcomed faster.

-The visual perception and recognition in a city can make attending of the activities as well as economy and communication faster.

-The common spaces in cities should be multifunctional, flexible and optimal. That is another factor which can save time. These factors could be added but 
there is one thing that should never be forgotten while gaining speed in life styles, aesthetical values and comfort criteria should never be forgotten which lead to optimal means of space planning on the basis of speed in the sustainable city.

\section{Conclusion}

As a conclusion of this study we can say that the term sustainability should be analyzed through the dynamic meaning of life styles, which intersects the speed criteria. If ordinary life in a city is both comfortable, peaceful and at the same time fast and easy, then the solution of the speed criteria can automatically bring sustainable and contemporary conditions.

\section{References}

[1] Braudel F., The Structures of everyday life: The limits of the possible Civilization and Capitalism: $15^{\text {th }}-18^{\text {th }}$ Century, University of California Press, 1992.

[2] Camagni R. and Gibelli M.C., Reseaux de villes politiques urbaines', in Flux no:16, Paris, 1994.

[3] Camagni, R. Global Network and Local Nfilieu, in S. Conti, E. Malecki and P. Oinas (eds), 'The industrial enterprise and its environment: Spatial Perspectives', Avebury, Aldershot, 1995.

[4] Gordon R., Internationalization, Multi-nationalization, Globalization: Contradictory World Economics and New Spatial Division of Labor, Working Paper Series, Centre for the Study of Global Transformation, University of California, Santa Cruz, n. 94-10, 1994.

[5] Habermas, J., The theory of communicative action, Vol. 1 Boston, M.A.: Beacon Press, 1994.

[6] http://www.unchs.org/unchs/english/transpor/transp.htm.

[7] http://www.balsoy.com/Turkiye/inpictures/pi/ankara04.html.

[8] http://www.bamjam.net/Turkey/Ankara.html.

[9] http://tr.wikipedia.org/wiki/Resim:T\%C3\%BCrkiye-b\%C3\%B6lgeler.png.

[10] http://tr.wikipedia.org/wiki/Ankara_\%28il\%29. 